\title{
Ageing Well with CSCW
}

\author{
Ann Light ${ }^{1}$, Tuck W Leong ${ }^{2}$ and Toni Robertson ${ }^{2}$ \\ ${ }^{1}$ University of Sussex, UK; ${ }^{2}$ University of Technology Sydney, Australia \\ lann.light@sussex.ac.uk, ${ }^{2}$ tuckwah.leong@uts.edu.au, \\ ${ }^{2}$ toni.robertson@uts.edu.au
}

\begin{abstract}
This paper rethinks the role of technology in the life of older people by critically considering the discourses around ageing: drawing on insights from literatures on active ageing, findings from two studies conducted with older citizens and prevalent understandings of old age in technology design. It argues for a departure from the deficit model of old age, to an understanding that reveals older people's agency in the ageing process and the work they do to manage their capacity to age well. This reframing of ageing and the ageing population offers new insights to CSCW and suggests new goals to support when designing technology for older people - goals that are more cognizant of people's agency and their desires to manage their evolving experiences of the ageing process. We conclude with characteristics of the technologies we might develop.
\end{abstract}

\section{Introduction}

This paper critically considers design for older people, drawing on insights from the literatures on active ageing and presentations of old age in technology design. We explore how we might contribute to the positioning of CSCW by studying practices that constitute the work of active ageing to achieve the goals of ageing well. This reflection on ageing seeks to develop the field by departing from solution-focused approaches that take a deficit model of old age. Our aim is to broaden views about the ageing process: from the rhetoric of assistance and vulnerability to one that prioritizes the agency of older people and how this plays out in the connections and relations between people, their living environments, technologies, and artefacts. We complement our discussion with findings from two studies grounded in older peoples' own interests, priorities and everyday 
practices. In doing so, this paper does not present design templates or solutions, but offers a series of considerations to inform design discussion and reflection.

\section{Background: ageing as a process}

To capture the subtleties of ageing, with its cultural and political dynamics, we start with the World Health Organization definition of active ageing:

the process of optimizing opportunities for health, participation and security in order to enhance quality of life as people age [which...] allows people to realize their potential for physical, social, and mental well being throughout the life course and to participate in society according to their needs, desires and capacities, while providing them with adequate protection, security and care when they require assistance. (www.who.int/ageing/active_ageing/en/).

From a CSCW perspective, we consider active ageing as the work of preparing for new life stages when interests, values, conditions and capabilities may change. In doing so, we can recognize continua in ageing (eg chronological, cultural, physical) and structural and emotional discontinuities (retirement, bereavement) that life as lived across many parts of the world in the 21 st century introduces. Malanowski (2009) presents four phases of old age: pre-retirement; independent living as a retiree; early dependent living (with increasing limitations); dependent living up until death. We regard these as useful to think about design needs, but add the obvious point that active ageing can begin when young - being a lifelong condition to which different people choose to give different amounts of attention and preparation - and identify ageing as a process rather than a series of states.

If we regard ageing as a process, rather than old age as a state, what changes? Do we get a better model? These questions help us avoid thinking of older people as a single vulnerable group with uniform needs that remain static. SchröderButterfill and Marianti (2006) suggest "current research rightly criticizes blanket assumptions of older people's dependence and vulnerability" (p4). For instance, socio-cultural participation has been shown to positively influence older people's health (Carstairs and Keon 2008), as does reciprocity - having something to offer as well as to take - (Fyrand 2010), while even a chance to show efficacy enhances life and prolongs health (Shepherd et al 2008). At its simplest, "the mere act of decision-making may be a way for the heavily dependent to remain engaged with life" in contrast with the negative affect associated with " giving in"” (Boudiny 2013, p1091). Within the design literature, Brandt et al (2011) suggest thinking in terms of 'situated elderliness' to avoid simplistic descriptions. Lindley et al (2009) suggest that older people's communication patterns become slowly more selective and considered. And Light shows the transformative impact possible in participatory projects, reporting a participant's feelings: 'Asked what she derived from the experience [of the project, she...] spoke of regaining her identity: "We went in as old people and came out as people with our own thoughts and 
agendas."' (2011). Here we see the extent to which people may be aware of their ageing and the social and structural categorization that arises from it.

However, technology design research has shown a tendency to fasten on older people's need for assistance as its principal concern, at worst treating older people as a single needy and costly demographic; at best regarding care in old age as a complex site of negotiation, but frequently ignoring the other half of the equation: what quality of life might mean and how we seek to maintain it as our capacities and priorities change. Vines et al (2015) categorize the HCI literature on old age in four discourses: of health economics, (lack of) socialisation, homogeneity and deficit. Influential discourses reinforce this:

The term `assistive technology device' means any item, piece of equipment, or product system, [...] that is used to increase, maintain, or improve functional capabilities of individuals with disabilities. (US, The Assistive Technology Act of 1998 [105-394, S.2432]).

Technology is given as a solution, to make up for and even cancel out human decline. Blythe et al note that assistive technology is "often ugly or stigmatising" (2005, p677), reinforcing a particular view of older people in society.

In (even notionally) adopting a deficit model, we ignore people's idiosyncratic features, as we do in many design contexts. But when we do it here, we reduce diversity of hopes, fears, needs, experiences, characteristics, interests and motivations, as well as people's own awareness of and management of ageing, to a stereotypically incompetent user, both in need of assistance to live and also to control their technology.

Boudiny (2013) warns against setting up expectations of particular types of competence in defining active ageing, causing the 'older old' to feel inadequate, but she devotes more of her policy critique to highlighting definitions of ageing that make all older people feel misunderstood, marginalized or patronized. Instead, the case is made for a rounded approach: "policies on ageing are often characterized by a dichotomy, targeting either healthy older adults by promoting active participation and self-responsibility or dependent older people by viewing them primarily as recipients of care ...In our view, however, being engaged in life and being dependent are not mutually exclusive." (Boudiny 2013, p1087).

As would be expected in a field such as CSCW, which places great importance on close observational studies of practice, there are already good examples in the literature focusing on the work involved in specific areas of ageing and home care, such as Procter et al (2014) and Bratteteig and Wagner (2013). We suggest a dynamic model of ageing can achieve recognition of the multidimensionality of the design space, not just to learn to design existing tools better, but to reveal new opportunities to be creative with computer-supported collaboration. 


\section{Rethinking the ageing process: two studies}

In this section, we describe two studies (one Australian, one British) that sought to understand ageing from the perspective of people thinking about their present and future interests, values needs and spaces. Both were explorative, involving qualitative work with a wide range of participants in the second half of life.

\section{Ageing Well - an Australian study}

In a project about the potential role of technology in maintaining good habits into old age, researchers conducted semi-structured interviews with Australians between the ages of 55 and 75 . The demographic for the interviews was relatively narrow: white, middle-class and living in the eastern states of Australia. The first series (20 interviews) sought demographic and experiential data, including participants' definitions of ageing well, fitness and activity levels, community and social engagement, use of and attitudes to various information and communication technologies, future work and retirement plans, and current practices around keeping in touch with friends and families (Robertson et al, 2012, 2013). This group was a mix of working, semi-retired and fully retired people; some were very computer literate while others were comfortable only with (mobile) phone use and email. The second series (20 interviews) involved technology-literate participants who already used internet connections at home. These interviews linked understandings of ageing well to participants' domestic environment, the significant objects and spaces within it, and how these were used and inhabited.

Analysis reveals that participants' views of what ageing well meant to them were remarkably similar. Good health, mobility and fitness, independence, social interaction and community involvement were identified as central to maintaining current and future well-being. Maintaining good health and a level of fitness was considered central to keeping mobile and maintaining the social agency and physical independence that each of our participants valued highly. Participants all expressed their desire to maintain, for as long as possible, their capacity to experience and engage in life. They revealed themselves to be mindful of ageing and its approaching needs and interested to age in step with the networks, spaces, technologies and opportunities round them, but to stay in control.

Yet, while participants' views of ageing well were highly consistent, there was great diversity in what it would mean for each participant to maintain good health, mobility and fitness, having aged differently and responded differently to the ageing process. Everyone wanted to maintain social agency and relationships with families and friends, yet social networks and how these were experienced and managed were very different. And while all participants were already using digital technologies, again there was difference in the way technology was used. 
Significantly, participants had little interest in tools designed specifically for 'the aged'. Instead they wanted to use the same technologies that 'everyone else' used. There was an expectation that tools would be designed without the negative associations of assistive, age-defined and deficit-focused technologies. But, as Lindley et al (2009) found in their study of communication patterns, participants were selective in what they were prepared to use and how they apportioned their time, especially in learning new approaches. They were willing and able to learn and use tools they recognized as useful, particularly if they could be seen to support central aspects of ageing well, such as maintaining independence, social agency, their sense of their 'cultural self' and ability to remain in their own home. Participants had appropriated a number of communications tools into their everyday lives and were in various stages of engaging with newer social technologies. The use of word processing, email and various web services, such as online banking, was common. There were different levels of familiarity with some of the newer tangible technologies and little interest in expanding use of those currently available. In other words, the interviews provided a snapshot in the ongoing appropriation of new technologies that were not specifically agerelated, but part of the general social, technological and physical infrastructure in which ageing people live. If there was a tendency related to age, it was that judgments on a tool's value involved different factors.

The cultural self that ageing people seek to maintain pertains to cultural origins, life histories, gender roles, values and generation. The interviews omitted any direct multi-cultural element though just over a third of the participants were migrants. But a related pilot study indicates that asking questions of older people from different Australian communities would yield an even wider set of priorities and choices. A study conducted by postgraduate students interviewing elderly migrants now living in New South Wales looked at how cultural values shaped views and expectations. For instance, among the elderly Chinese interviewed (from Hong Kong or China), growing older did not mean living alone or away from their families. Instead, a lot of those interviewed lived with their children, especially if widowed. Despite diaspora, older people were in close proximity to the rest of their clan. And asking these questions of Indigenous communities would yield another set of practices that are different from the ones reported here.

\section{FLEX - a UK study}

The Flexible Dwellings for Extended Living (FLEX) project worked with a broad cross-section of city-dwelling mature adults in the UK. It took a participatory look at the social factors of wellbeing as we age 'in place' to learn how neighbourhoods might tackle the promotion of sociality together within and across generations and resist trends that encourage social isolation - from erosion of meeting places to the advent of environmentally-sealed, socially-barricaded smart homes. FLEX worked specifically with the idea of conviviality or 'living 
together'; it did not specify interest in technology. We use this second study to consider further how participants spoke about what they value in the social realm.

City dwellers in England and Scotland, aged 43-82, from diverse backgrounds and lifestyles (sourced through mailing lists to very different housing areas) came to talk together at tea parties about how they want to live as they age. Everyone who attended had volunteered, so they were not a typical cross-section but people with motivation to join events (see Light et al 2013, Light and Akama 2014 for more on methodology). Invites to the discussions avoided targeting 'older people' as such, with a flier labelled 'Living Sociably as we Age' and an invitation to ask 'What might we do as we grow older to live our lives as fully and convivially as possible in our homes and domestic spaces?'. Participants reflected together in ad-hoc groups, prompted by questions on the themes of 'home' and 'sharing'. They explored how social and spatial elements of their world could be configured to improve a sense of shared space or time (e.g. street-parties or co-gardening) and how these afford relative strangers occasion to meet and talk. Highly prominent were discussions on a) taking the initiative to keep social - and useful in one's community, and b) mixing across generations. We use these here to give specific examples of how important social agency and cultural identity are to people considering ageing.

Participants noted society's increased desire to protect vulnerable members, such as young and very old people, and how it works counter-productively by making behavior seem risky that has traditionally strengthened social networks (neighbours involved in childcare, sharing, acts of kindness and 'popping in'). As the participants put it: 'generosity of spirit encourages people to communicate better' and, in Britain, you need 'the odd eccentric in a group to start the ball rolling' (tea party, Newcastle). Fired by this theme, one participant ("Jill”), a retired woman renting with her husband, became eloquent: 'I believe that if you take that first step, people will be grateful. Take the risk, because in all sorts of ways we're really becoming such a risk-averse society, aren't we?' Jill goes on to describe an occasion when she establishes contact with the student household upstairs: "There was a mix up and we ended up with two pizzas and I just knocked on one of the flats. ...I said "Would you like this pizza? The pizzeria has given us this free because, you know... and do you like pepperoni?" and he said "I do now.". And two days later, he said: "That was great. I really enjoyed my pizza."'. Jill's joy at the encounter and her memory of it is palpable.

Jill is clearly taking initiative in setting up good neighbourly relations and is pleased to have done so, but we can see other factors at play. She tells the story in the context of dismay at an increasingly 'risk-averse society'. She is both engaged in an analysis of society and acting (perhaps in retrospect) to counteract the trend she dislikes. She is making herself socially useful as well as socially connected. We are not surprised that someone who values sociality should come to discuss 'social wellbeing as we age'. But we draw attention to the work that Jill is doing, 
first in visiting the neighbour and then in telling the story in this context. She is asserting her values, her desire to live by them and the manageable way that she can perform this in her immediate world. By 'work', here, we mean activities considered 'necessary or useful in a practical way' (Schmidt 2011, p. 375).

The second theme is prefigured already: a general interest in avoiding the old people ghetto and 'that we stop separating older and younger people' (tea party, Dundee). We have heard it in the first study, where ageing Australians reject customized technology, and, in Jill's account of crossing the generation gap with pizza. Again participants saw this in broad societal terms: that youngsters would be more courteous to their elders if they knew them. But they also considered more subtle mixing, discussing the policy of council-run classes held at sheltered accommodation for the elderly that are open for anyone to attend, and which they attend because 'the teacher is good'. Photoshop classes are popular, as is dancing. 'It's a socialized intermixing of younger and older pensioners and younger people just coming up to pension age. Some of them are able to do it all, the dancing..., other ones like, say, do the cooking... and other ones just sit and watch and I think it's very good for them' (Dick, social housing).

Again, we see the self-perception as active. Attendees had various incapacities and mobility problems, but none saw themselves as part of a vulnerable group. Instead, they described concern for more aged neighbours. We see recognition of people's different needs and how they can be managed and a welcoming of policy that mixes people. We see the selectivity in joining in - because of a 'good' teacher - and note the popularity of Photoshop, a digital tool.

Reflecting, groups in both cities observed that mere recognition of issues of ageing and sociality by individuals and across neighbourhoods could make a real difference to how community reliance is formed.

To sum up, establishing social agency and cultural identity is integral to the work of coordinating with others. It is such an obvious and necessary activity that its maintenance only becomes articulated as a goal of ageing well during close examination. In the Australian study, people described this to researchers. In the British study, because of the different method, it was possible to see it enacted.

\section{Discussion: CSCW for ageing populations}

It would be easy to conclude from this argument about the diversity of older people's experience that any tool that works for the general population could be used by older people and this would avoid discrimination. That is, of course, true. We can point to older people's rich potential for informing the design of devices and networks for all populations, not just the old, bringing familiarity with and acceptance of change, insight into shifts in technology, felt engagement with what younger people regard as history and many other qualities. We can suggest this potential is currently undervalued worldwide (though not by all cultures). 
Yet, we can go further. Not only do many people have a strong sense of what they need, witnessed in our samples, but the acts of securing it contribute to the potential for a healthier old age. We can dignify ageing - and help people live well for longer - by acknowledging ageing as a physical, mental, emotional and structural process that people work to learn to manage as part of that process, even as their capacities change. We can design with this insight in mind and design to ease tensions created by national policies (including policy on retirement age and conditions, workers' rights, power of attorney, etc.) that cannot attune to the needs of each person. Adopting this perspective, we can derive characteristics with some significance for CSCW research:

Flux: Ageing selves reflect the lives they have led. They are old enough for genetic, cultural and environmental influences to have inscribed themselves, along with experiences, such as their work, access to health care, good food and a safe environment, their communities and the kinds of social activities, cultural mores and expectations these provided, as well as various random life events and accidents. This inscription is not static, but etches more deeply as time passes. People face a continuum of small changes as well as some abrupt transitions. Day-to-day living must be managed more carefully as the effects become more pronounced. More maintenance and coordination work is needed over time to support the status quo, such as living at home, keeping up with friends, etc.

Adjustment: As Boudiny reminds us (2013), people do not make a choice between dependency and independence, but experience a gradual reevaluation of their roles relative to others and their place in their different worlds, as energy levels and capacities change. What remains is the desire to engage; what changes is what it means to engage and, gradually, the methods of engagement.

Agency: All participants in the studies desired to maintain social agency and cultural identity - to be valued as people with things to contribute and to share in. Performing these as part of social life is a transcendent but unquantifiable goal in ageing well. Being able to do the work of belonging, taking initiative and getting counted is often more meaningful than 'independence' as such.

Prioritization: As energy dwindles and the time taken to achieve tasks grows, selectivity becomes more marked. More demanding and less valued tasks and pleasures are let go, as are the more onerous aspects of their coordination.

Willingness: In the face of loss, people unfold unexpected substitute skills, collaborative relationships or creative strategies to overcome limitations (Boudiny 2013). Our studies found that, when people see a rationale for support tools to prevent them losing whatever they fear losing, they will overcome obstacles to accomplish their use. This is in balance with capacity and confidence.

\section{Types of Tool}

Working with this set of characteristics, what difference might it make to our designs? Boudiny says of offering support: "The aim is to achieve a partnership in 
which two destructive extremes are avoided, i.e. expert-based decision-making without reference to older adults' perspectives versus simply leaving older persons to express what they want in an unsupported way" (2013, p1092). The same could be said of the role of a tool or socio-technical network. We contrast the term assistive with enabling to put the emphasis on what the technologies achieve for the user (enabled), rather than what they claim by way of contribution (assisting). And we end our consideration of ageing and technology design with possible characteristics of the technologies to be built:

Enabling: Supporting the ageing person in their ever-evolving coordination of mechanisms for maintaining the status quo, so that ageing does not impinge on the execution of their goals, but allows them to keep doing more for longer.

Extending: Lengthening the period of fulfilled and self-managed living and reducing the ailing morbid phase, by making it easier to assemble, judge and grow the technical, medical and social networks of support needed.

Blurring: Helping to ease the transitions between Malanowski's (2009) first three phases of old age: pre-retirement; independent living as a retiree; early dependent living (with increasing limitations), so that personal management processes can run smoothly despite structural change.

Adapting: Following the person as they become more selective about what they do, but also helping them choose their path, thus acknowledging and supporting the work of managing ageing, as well as the ageing process.

We have seen that diversity as we age is multi-dimensional and unpredictable. The recognition of the specificity of ageing selves and the activities available to them - including appropriation of new and emerging technologies - foregrounds the further recognition that ageing people remain embedded within their everchanging social and cultural worlds. Indeed it is that embeddedness that we seek to maintain as we grow and continue to age.

Our aim is to help more people lead rich and fulfilling lives for longer, but we acknowledge that pressure on support systems in many countries has led to political interest in enabling people to live longer at home ('ageing in place') and promoting older people's input into 'core' (ie domestic, non-remunerated, societal) and financial economies. Both motivations argue for a turn to exploring the management of the ageing process in such a way people's own interest in ageing well is allowed to contribute to their wellbeing. We argue that technology can have an enabling role in this process, with insights from CSCW helping to ensure that the coordination work of ageing well is understood and incorporated.

\section{Acknowledgments}

We thank our participants and the AHRC for funding Flexible Dwellings for Extended Living (grant no. ???) The Australian study was funded by Australia 
Research Council Discovery Grants Program. Jeannette Durick contributed to the original research in this study.

\section{References}

Boudiny, K. (2013): 'Active ageing: from empty rhetoric to effective policy tool', Ageing and society vol. 33, no. 6, pp.1077-1098.

Blythe MA, Monk AF, Doughty K. (2005): 'Socially dependable design: The challenge of ageing population for HCI'. Interacting with Computers, vol. 17, no. 6, pp. 672-689,

Brandt, E., Binder, T., Malmborg, L. \& Sokoler, T. (2010): 'Communities of everyday practice and situated elderliness as an approach to co-design for senior interaction'. Proceedings of $\mathrm{OzCHI}$ 2010, ACM, pp. 400-403.

Bratteteig, T. and Wagner, I. (2013): 'Moving healthcare to the home: the work to make homecare work'. Proceedings of ECSCW'13, pp. 141-160.

Carstairs, S. and Keon, W. J. (2008): 'Issues and Options for an Aging Population'. Second Interim Report, Special Senate Committee on Aging, Ottawa

Fyrand, L., (2010): 'Reciprocity: A Predictor of Mental Health and Continuity in Elderly People's Relationships? A Review'. Current Gerontology and Geriatrics Research

Light, A. (2011): 'Democratising Technology: Inspiring Transformation with Design, Performance and Props', Proceedings of CHI'11, pp. 2239-2242

Lindley, S. E., Harper, R. and Sellen, A. (2009): 'Desiring to be in touch in a changing communications landscape: attitudes of older adults'. Proceedings of CHI'09, pp. 1693-1702.

Malanowski, N. (2009): 'ICT-based applications for active ageing: challenges and opportunities'. In Cabrera, M. and Malanowski, N. (eds), Information and Communication Technologies for Active Ageing: Opportunities and Challenges for the European Union. IOS Press, Amsterdam,

Procter R, Greenhalgh T, Wherton J, Sugarhood P, Rouncefield M, Hinder S. (2014): 'The Dayto-Day Co-Production of Ageing in Place'. JCSCW, vol 23, pp. 245-267

Light, A., Milligan, A., Bond, L., McIntosh, L. and Botten, C. (2013): 'High Tea at the Conviviality Café: Research Tool or Design Intervention?' Proceedings of Research through Design Conference 2013

Light, A. and Akama, Y. (2104): 'Structuring Future Social Relations: The Politics of Care in Participatory Practice', Proceedings of PDC 2014, ACM, pp. 151-160.

Robertson, T., Durick, J., Brereton, M., Vetere, F., Howard, S. and Nansen, B. (2012): 'Knowing Our Users: Scoping Interviews in Design Research with Ageing Participants', Proceedings of OzCHI 2012, ACM, pp. 517-520.

Robertson, T., Durick, J., Brereton, M., Vaisutis, K., Vetere, F., Howard, S. and Nansen, B. (2013): 'Emerging Technologies and the Contextual and Contingent Experiences of Ageing Well”, Proceedings of Interact 2013, pp. 582-589.

Schmidt, K. (2011): 'The concept of 'work' in CSCW', in Computer Supported Cooperative Work (CSCW), vol. 20, nos. 4-5, pp. 341-401

Schröder-Butterfill, E. and Marianti, R. (2006): 'Understanding Vulnerabilities In Old Age', Ageing And Society, vol. 26, no. 1, pp. 3-8.

Shepherd, G., Boardman, J. and Slade, M. (2008): 'Making recovery a reality'. Sainsbury Centre for Mental Health

Vines, J. Pritchard, G., Wright, P., Olivier, P. Brittain, K. (2015): 'An Age Old Problem: Examining the Discourses of Ageing in HCI and Strategies for Future Research', ToCHI, vol. 2 , no. 1 , article 2 . 